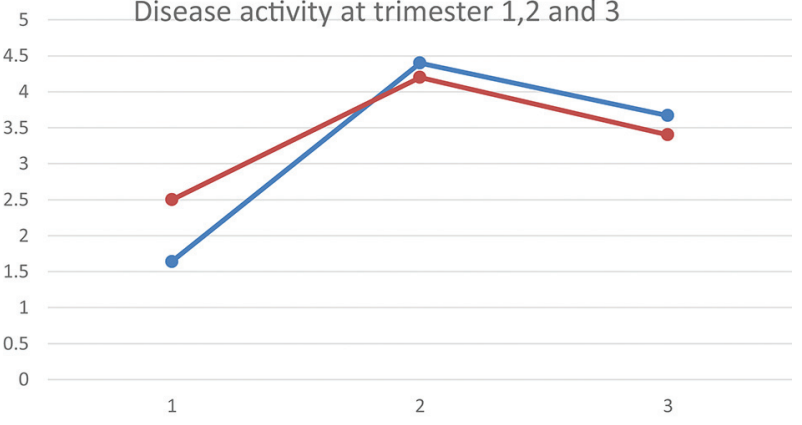

$\longrightarrow$ Disease activity (current) $\longrightarrow$ Disease activity (before)

Abstract AB1229 Figure 1. shows DA according to trimester before and during pregancy

Conclusion: In our group of pregnant patients with Msk diseases the overall disease activity is the same during pregnancy and before as measured by a VAS. Looking at the diseases patients with RA and SpA showed some reduction and patients with CTDs and APS showed an increase both not statistically significant.

Looking at reported VAS according to trimester of pregnancy, it is in the 1 st trimester that pregnant patients report reduced activity.

Acknowledgement: Thanks to pregnant women filling the questionnaire

Disclosure of Interests: None declared

DOI: 10.1136/annrheumdis-2019-eular.2706

\section{AB1230 DISEASE ACTIVITY OF RHEUMATIC DISEASES DURING PREGNANCY COMPARED TO REPORTED DISEASE ACTIVITYPRIOR TO PREGNANCY AS OBTAINED FROM AN ANTENATAL RHEUMATOLOGY OBSTETRIC COMBINED CLINIC AND MODE OF DELIVERY}

Euthalia Roussou', Josie O'heney ${ }^{2}$, Victoria Sampson ${ }^{3}$, Asma Aziz ${ }^{4} .{ }^{1}$ Barking Havering and Redbridge University Hospitals NHS Trust, Rheumatology, Romford, United Kingdom, ${ }^{2}$ Barking Havering and Redbridge University Hospitals NHS Trust, Obstetrics and Gynaecology, Romford, United Kingdom; ${ }^{2}$ Barking Havering and Redbridge University Hospitals NHS Trust, Obstetrics and Gynaecology, Romford, United Kingdom; ${ }^{2}$ Barking Havering and Redbridge University Hospitals NHS Trust, Obstetrics and Gynaecology, Romford, United Kingdom

Background: A Rheumatology Obstetrics Care Clinic (ROCC) was established at our ante natal unit to ensure specialist care for women with complex rheumatological conditions (RC).

Although patients are often counselled about a likely improvement in their $\mathrm{RC}$ in pregnancy, this was not the experience of our patients' group from the ROCC.

Objectives: To obtain pregnant women with RC disease activity (DA) scores during and prior to pregnancy. To assess modes of delivery (MoD) and compare them to our general non arthritic population MoD.

Methods: Patients suffering from any RC attending a dedicated highly specialized antenatal ROCC were given 2 separate $10 \mathrm{~cm}$ visual analogue scales (VAS) asking them to grade on each one of them the current ( at ROCC) DA and their perceived DA prior to pregnancy. Electronic delivery records were used to collect obstetric and foetal outcomes. SPSS was used for statistical analysis and chi square to assess the difference between the 2 groups.

Results: Data from 54 patients who attended the ROCC included of whom 50 were analyzed. At the time of presentation mean age $( \pm s d)$ was 33.4 years $( \pm 4.29)$ range $22-43 y$ while age of disease presentation was $25.5( \pm 8.06)$. The weeks $(\mathrm{w})$ of pregnancy during ROCC were (mean) $22.2( \pm 8.6)$ range 8-37 w. ESR (mean) was $27 \mathrm{mmHg}( \pm 21.7)$, CRP $13.6 \mathrm{mg} / \mathrm{L}( \pm 14.18)$. DA at presentation on VAS was $4.24 \mathrm{~cm}( \pm$ $2.8)$ and prior to pregnancy was $4.24 \mathrm{~cm}( \pm 3.07)$.

The recorded diseases were: Connective Tissue Diseases $(C T D)=n=18$ (33.3\%) Spondylo-arthropathies (SpA) $\mathrm{n}=16 \quad$ (29.6\%), Rheumatoid Arthritis $($ RA) $n=9(16.7 \%)$, Antiphospholipid Syndrome (APS) $n=7$ (13\%) and other $\mathrm{n}=4(7 \%)$ The group of other (Still's disease 1, Juvenile idiopathic arthritis 1, fibromyalgia 1 and knee pain 1) were excluded from analysis.

Looking at the disease groups RA and SpA patients' showed a reduction in the reported DA during pregnancy while CTDs and APS showed an increase; neither was statistically significant (ss).
Delivery outcomes available on 35 patients revealed that 25 of $35 \mathrm{RC}$ patients $(71.4 \%)$ achieved a vaginal delivery with 5 of $25(20 \%)$ requiring assisted delivery and 10 of $35(28.5 \%)$ had a Caesarean section (CS). These percentages are comparable with non arthritic patients.

Conclusion: In our group of pregnant patients with RC the overall DA is the same during pregnancy and prior to conception. DA according to diseases showed that women with RA and SpA had a reduction in DA and those with CTDs and APS had an increase.

The MoD showed similar percentages in vaginal and CS delivery rates as per healthy population suggesting that MoD is not impacted by RC.

Acknowledgement: Patients for filling the ROCC questionnaire

Disclosure of Interests: None declared

DOI: 10.1136/annrheumdis-2019-eular.2634

\section{AB1231 INCIDENCE OF TUBERCULOSIS IN PATIENTS WITH RHEUMATIC DISEASES USING TNF INHIBITORS: A SYSTEMATIC REVIEW}

Natália Sartori, Nicole Andrade, Rafael Chakr. Hospital de Clínicas de Porto Alegre, Department of Rheumatology, Porto Alegre, Brazil

Background: The TNF inhibitors (anti-TNF) are indicated for the treatment of several rheumatic diseases, but their use is associated with an increased risk of tuberculosis. Many measures of preventive measures have been adopted, but some groups of patients appear to be at greater risk of developing infection.

Objectives: The primary objective is to estimate the incidence of tuberculosis in patients with rheumatologic diseases exposed to anti-TNF. The secondary objectives are to evaluate the incidence of tuberculosis by region and subgroups of diseases, to assess the presentation of tuberculosis in these patients and the time elapsed between onset of anti-TNF and the development of active granulomatous disease.

Methods: A systematic review of the literature was conducted in Medline (Pubmed, Embase), Cochrane Library and Lilacs with inclusion of observational studies. The selection of articles was performed by two independent reviewers and the disagreements were resolved by consensus The primary endpoint was described in measure of incidence and secon dary outcomes through subgroup analyzes and means comparisons.

Results: We included 54 observational studies with a total of 98,483 patients exposed to anti-TNF. Among the exposed patients, 947 cases of tuberculosis were documented (pulmonary form in $62.2 \%$ of cases), with a cumulative incidence of 9.62 cases per 1,000 patients exposed $[\mathrm{Cl}$ 9.01 - 10.23]. Regarding TB incidence considering the different continents, we found the following distribution: South America with 11.75 per 1,000 patients exposed [Cl: 7.17 - 16.33], North America with 4.34 per 1,000 patients exposed [Cl: 3.31-5.38], Europe with 6.28 per 1,000 patients exposed [Cl: 5.34 - 7.14] and Asia with 13.47 patients per 1,000 exposed [Cl: 12.44 - 14.49]. There were no significant differences in TB incidence among the described diseases (rheumatoid arthritis, ankylosing spondylitis, psoriatic arthritis and juvenile idiopathic arthritis). The mean time of use of the medication until the endpoint was 14.49 months.

Conclusion: The overall incidence of TB in individuals with rheumatic diseases using anti-TNF was 9.62 cases/103 patient-years, being higher in South America and Asia compared to North America and Europe. Most cases occurred in the first $X X$ months of use and the predominant form was pulmonary. There were no differences in incidence between diseases.

\section{REFERENCES}

[1] Pérez-Sola MJ, Torre-Cisneros J, Pérez-Zafrilla B, Carmona L, Descalzo MA, Gómez-Reino JJ. Infections in patients treated with tumor necrosis factor antagonists: incidence, etiology and mortality in the BIOBADASER registry. Med Clin (Barc). 2011;

[2] Yonekura CL, Oliveira RDR, Titton DC, et al. Incidência de tuberculose em pacientes com artrite reumatoide em uso de bloqueadores do TNF no Brasil: dados do Registro Brasileiro de Monitoração de Terapias Biológicas BiobadaBrasil. Rev Bras Reumatol. 2017;

[3] Dixon WG, Hyrich KL, Watson KD, et al. Drug-specific risk of tuberculosis in patients with rheumatoid arthritis treated with anti-TNF therapy: Results from the British Society for Rheumatology Biologics Register (BSRBR). Ann Rheum Dis. 2010;

[4] Askling J, Fored CM, Brandt L, et al. Risk and case characteristics of tuberculosis in rheumatoid arthritis associated with tumor necrosis factor antagonists in Sweden. Arthritis Rheum. 2005;

[5] Lee SK, Kim SY, Kim EY, et al. Mycobacterial infections in patients treated with tumor necrosis factor antagonists in South Korea. Lung. 2013. 
Disclosure of Interests: None declared

DOI: 10.1136/annrheumdis-2019-eular.7921

\section{AB1232 RHEUMA-VOR: A PROOF-OF-CONCEPT NETWORK STUDY FOR THE IMPROVEMENT OF RHEUMATOLOGICAL HEALTH CARE THROUGH COORDINATED COOPERATION}

Matthias Dreher ${ }^{1}$, Gunter Assmann ${ }^{2}$, Kirsten Hoeper ${ }^{3}$, Konstantinos Triantafyllias ${ }^{4}$ Jan Zeidler ${ }^{5}$, Harald Binder ${ }^{6}$, Reinhold E. Schmitt ${ }^{7}$, Andreas Schwarting ${ }^{1,4}$

${ }^{1}$ University Medical Center of the Johannes Gutenberg University Mainz, Division of Rheumatology and Clinical Immunology, Mainz, Germany; ${ }^{2}$ Saarland University Medical Center, Rheumatology, Homburg, Germany; ${ }^{3}$ Medizinische Hochschule Hannover, Center for Rheumatology Lower Saxony e.V., Hannover, Germany; ${ }^{4}$ ACURA Center of Rheumatology Rhineland-Palatinate, Bad Kreuznach, Germany; ${ }^{5}$ Leibniz University Hannover, Center for Health Economics Research Hannover, Hannover, Germany; ${ }^{6}$ University Medical Center Freiburg, Institute of Medical Biometry and Statistics, Freiburg, Germany; ${ }^{7}$ Medical School Hannover Department of Clinical Immunology and Rheumatology, Hannover, Germany

Background: Rheumatoid arthritis (RA), psoriasis arthritis (PsA) and spondyloarthritis $(\mathrm{SpA})$ are the most common chronic autoimmune rheumatic diseases. For all 3, the so-called "window of opportunity" [1-3] has been identified as the decisive factor affecting the outcome.

Objectives: The aim of the prospective study is to improve early diagnosis of RA, PsA and SpA and thus positively impact the quality of care for patients with the help of coordinating centers. The primary endpoint is the number of cases with an actual indication for immediate referral to a specialist in proportion to all reported cases.

Methods: The project establishes a network of the University Medical Center Mainz, the Medical School Hannover, the Center for Rheumatology Lower Saxony e.V., the University Medical Center Saarland, the ACURA Center of Rheumatology Rhineland-Palatinate, the Leibniz University Hannover and the University Medical Center Freiburg, local rheumatology specialists, the associations of statutory health insurance physicians and general practitioners and the 3 regional associations of the Deutsche Rheuma-Liga e.V. Covering 3 federal states, the network reaches approximately 13 million inhabitants.

Primary care providers are given access to screening questionnaires to document potential early cases of RA, PsA, and SpA, based on characteristic symptoms. These are evaluated by multidisciplinary teams at the regional coordinating centers. If they fulfill the criteria for referral, patients get an appointment at a cooperating rheumatology specialist within weeks. If a rheumatic disease is diagnosed, physicians and patients receive questionnaires on sociodemographic data, quality of life, functionality, medication, diagnosis and psychological aspects. After 12 months, the questionnaires are completed a second time. The collected data is compared with a matched reference group of the German Rheumatism Research Center. It is planned to screen up to 8.700 people within the 30-month survey phase that started in October 2017.

Results: Preliminary data will be presented at the conference. Currently, 2.400 patients have been screened, of which 400 patients were included in the study and 15 already underwent their follow-up screening.

Conclusion: Previous studies have shown positive results of coordinated cooperation among the relevant care providers. For example, 75 percent of the patients diagnosed with early RA within the ADAPTHERA network were in remission after 2 years (DAS28<2.6) [4]. Corresponding developments are expected in all clinical pictures for participants in RheumaVOR.

\section{REFERENCES}

[1] O'Dell, J.R., Treating rheumatoid arthritis early: a window of opportunity? Arthritis Rheum, 2002. 46(2): p. 283-5.

[2] Boehncke, W.H. and A. Menter, Burden of disease: psoriasis and psoriatic arthritis. Am J Clin Dermatol, 2013. 14(5): p. 377-88.

[3] Claudepierre, P., Spondyloarthritis: a window of opportunity? Joint Bone Spine, 2014. 81(3): p. 197-9.

[4] Lauter, A., et al. ADAPTHERA - Landesweit transsektorales Versorgungsnetzwerk für Patienten mit früher rheumatoider Arthritis zeigt anhaltende Remissionen in der Regelversorgung. Wunder Punkt: Die Triage. (2018). Manuscript.

Disclosure of Interests: Matthias Dreher: None declared, Gunter Assmann: None declared, Kirsten Hoeper: None declared, Konstantinos Triantafyllias: None declared, Jan Zeidler: None declared, Harald Binder: None declared, Reinhold E. Schmitt: None declared, Andreas Schwarting Grant/ research support from: GSK, Pfizer, AbbVie, Novartis, Roche, Speakers bureau: GSK, Novartis

DOI: 10.1136/annrheumdis-2019-eular.3666

\section{AB1233 PEOPLE WITH RHEUMATIC AND MUSCULOSKELETAL DISEASES CONNECT AND LEARN ABOUT HEALTH- RELATED ISSUES USING SOCIAL MEDIA}

Paul Studenic $^{1}$, Simon Stones ${ }^{2}$, Alessia Alunno ${ }^{3}$, Valentin Ritschl ${ }^{4}$,

Elena Nikiphorou ${ }^{5} .{ }^{1}$ Medical University of Vienna, Division of Rheumatology,

Vienna, Austria; ${ }^{2}$ University of Leeds, School of Healthcare, Leeds, United Kingdom; ${ }^{3}$ University of Perugia, Rheumatology Unit, Department of Medicine, Perugia, Italy; ${ }^{4}$ Medical Univerisity of Vienna, Section for Outcomes Research, Vienna, Austria; ${ }^{5}$ King's College London, Academic Rheumatology Department, London, United Kingdom

Background: Smartphone applications and social media (SM) are increas ingly used, transforming the way in which people communicate. Peer interaction, remote information access and community building are just some of the uses of SM, presenting novel opportunities and challenges, especially for people with chronic conditions such as rheumatic and musculoskeletal diseases (RMDs).

Objectives: To explore the perspectives of people with RMDs on using SM for health-related purposes.

Methods: A questionnaire-based survey, co-designed in English by rheu matologists and patient research partners and translated into German Italian, Spanish, Russian, French and Portuguese, was issued between May and December 2018, distributed via patient organizations and SM platforms. We report on the main quantitative exploratory analyses.

Results: A total of 992 participants started the survey; 853 (86\%) participants reached at least 25 of 31 questions and were subsequently included in analyses. Participants were from 56 countries, with $50 \%$ from the UK, Germany, Portugal and Spain; $11 \%$ were outside of Europe. $60 \%$ of participants reported a good or very good experience in the use of SM. More than half (56\%) were between 35 and 54 years, 90\% were female, $37 \%$ had $>1$ RMD and $62 \%$ were multimorbid.

The use of smartphones, SM, SM for health-related purposes was affirmed by $93 \%, 95 \%$ and $76 \%$, respectively. They started this in partic ular to connect with other people living with the same condition (58\%). In general, $50 \%$ use SM to seek medical information, treatment options and to exchange experiences. Facebook (58\%), Google+ $(17 \%)$ and YouTube (17\%) were the top three used platforms for health-related purposes; while Facebook (88\%), YouTube (50\%) and Instagram (47\%) were most popular for general use. Platforms, that are usually used are not always the preferred one for health-related purposes, since only $16 \%$ of Instagram, $28 \%$ of YouTube and $67 \%$ of Facebook users prefer the same for health-related purposes. The greatest advantage of SM is to acquire different experiences and exchange knowledge with peers. More than half voiced concerns regarding confidentiality and $21 \%$ were hesitant of disclosing their condition. Virtual appointments are still novel, since only $4 \%$ reported experience.

SM use and education were comparable between groups with different levels of multimorbidity, although health was poorer $(p=0.001)$ and they were older $(p=0.001)$. Participants more frequently considered that information provided by primary care physicians was inadequate $(p=0.014)$ and wanted to make their voice heard $(p=0.006)$, but at the same time were more skeptical about reliability of information on SM $(p=0.036)$.

Conclusion: The use of SM for health-related purposes is widespread among people with RMDs, mainly as a means to connect and exchange knowledge and experience, thus empowering individuals to better selfmanage their health. The strong concerns about confidentiality and better guidance of patients may improve health literacy and the relationship between the patient and the health care team, addressing new avenues and challenges in healthcare.

Acknowledgement: We would like to thank PARE in their support distributing this survey study.

Disclosure of Interests: Paul Studenic: None declared, Simon Stones Consultant for: SS has provided consultancy services to Envision Pharma Group, though this is not related to the contents of this abstract., Speakers bureau: SS has undertaken speaking engagements for Actelion, eyeforpharma, Four Health, Janssen and Roche, though these are not related to the contents of this abstract., Alessia Alunno: None declared, Valentin Ritschl: None declared, Elena Nikiphorou: None declared DOI: 10.1136/annrheumdis-2019-eular.6304 